\title{
A Simple and Reliable Method of Indwelling Urinary Catheter Fixation
}

\author{
Haque WMM
}

Two thousand years ago, bronze tubes were used for bladder catheterisation, $\mathrm{S}$ shaped bronze tube was found with other medical devices in the ruins of Pompeii ${ }^{1}$. However,use of indwelling catheter for urine drainage became widespread since 1936, after a U.S. manufacturer, Davol Rubber Company, introduced a soft rubber tube with an inflatable balloon that was based on a design by Frederick Foley ${ }^{2}$. Millions of patients are now using Foley's ctheter for various indications. In USA $25 \%$ of patients in acute care setup receive indwelling catheter ${ }^{3}$. Catheterisation is not a hazard freeintervention;it canlead to several complications including inadvertent catheter removal with urethral trauma.

According to a study by Lorente and colleagues in 2004, it was found that the incidence of accidental removal of indwelling urinary catheters was $2 \%$ per 100 catheter days ${ }^{4}$.

Inadvertentcatheter removal associated urethral trauma imposes undue morbidity, prolonged hospital stayand increased healthcare related cost.One of the most important but often neglected aspects of catheter care management is securing and fixing devices. Most of the concerned authorities including the Society of Urologic Nurses and Associates and the Centers for Disease Control and Prevention advocate the use of securing device to minimize the catheter related trauma and infections $^{5-7}$.

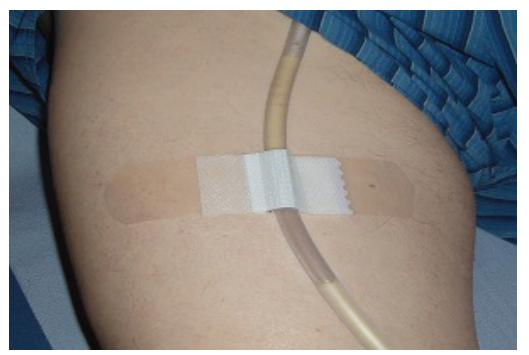

a. CliniFix

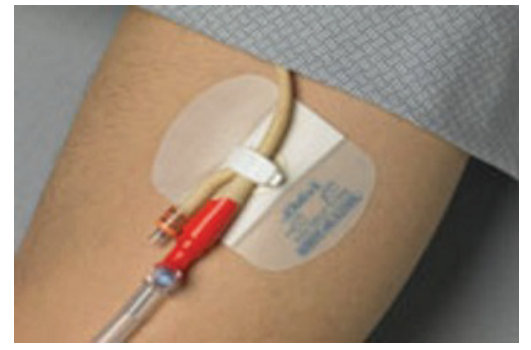

b. StatLock
Our usualpractice of fixation in ward with adhesive tape is not a dependable means of catheter securement ${ }^{8}$. It is vulnerable to minor traction; accidental pulling can dislodge the catheter causing urethral trauma.Adhesive tape loosens quickly and frequently, evenin many times failing to adhere to external catheter surface. Repeated use of adhesive tape causing sticky coating over catheter wall is a potential source of infection. Now a daysdirectadhesive tape fixation is not anymore advocated, more reliable fixation methodsshould be usedinstead ${ }^{8}$. Though improvised adhesive tapefixation is somewhat effective in reducing the transmitted force compared with an unsecured control, it is not as effective as newer technics ${ }^{9,10}$.Improvised devicesare usually made with adhesive tape applied to the abdomen or upper thigh. For example, a piece of tape can be applied to the skin and the catheter placed over it and secured with a second piece of tape that is attached to the first ${ }^{6}$.

Several manufactured fixing devices are available. Hanchett (2002) classifies them in 3 main categories ${ }^{8}$ (Fgure 1).

a) modified tapes (e.g. CliniFix),

b) adhesiveanchors (e.g. StatLockstabilisation device)

c) strapsandholders (e.g. CATH- MATE II tube retaining strap).

Figure 1 Different types of manufactured fixing devices

Dr. Wasim Md. Mohosin U1 Haque, Associate Professor, Nephrology, BIRDEM General Hospital, Dhaka, Bangladesh. Email: arko.amit@gmail.com 
Although these devices are designed to prevent urethral trauma, they can also cause new complications. Adhesive devices are associated with skin irritation and contamination thus cannot kept in place for more than 7 days. Strap-type devices can cause venous insufficiency,

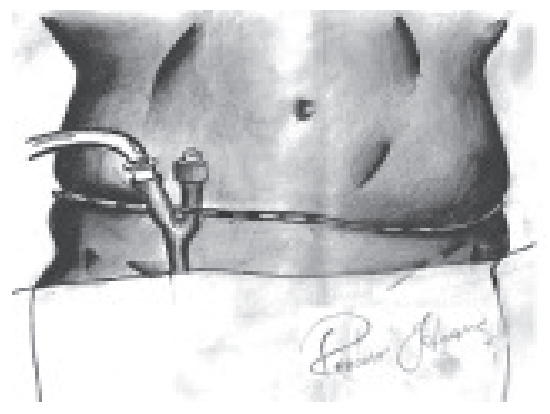

a) thrombophlebitis, even may lead to deep venous thrombosis ${ }^{11}$. Moreover, these devices are not available in our market. To secure the catheter in my practice,I use a simple personalised technique using gauze roll and micropore tape. Here catheter is fixed over abdomen by encircling loop of gauze roll (Figure 2).

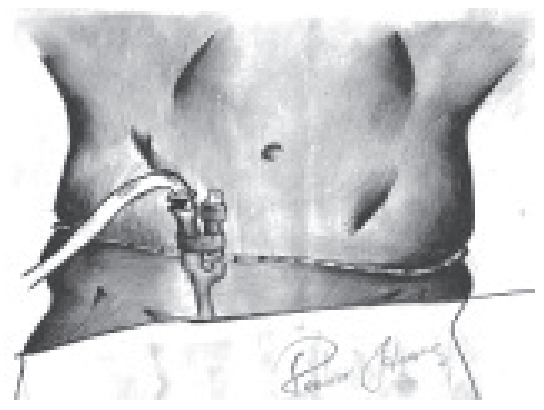

b)

Figure 2 Graphics of catheter fixation (sketch by Rebonto Haque)

First a gauze roll is placed around waist to create a loop, then balloon inflation port of Foley's catheter is placed beneath the loop, lastly two external ports (balloon port and urine drainage port) are fixed with micropore tape (Figure3).
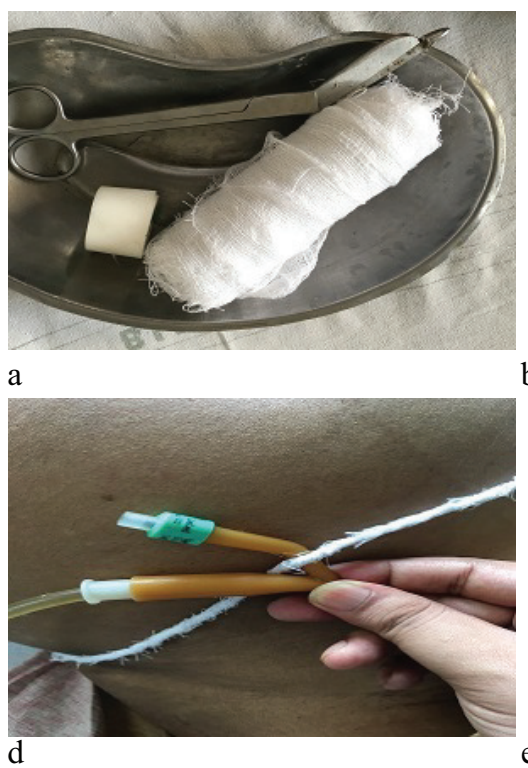
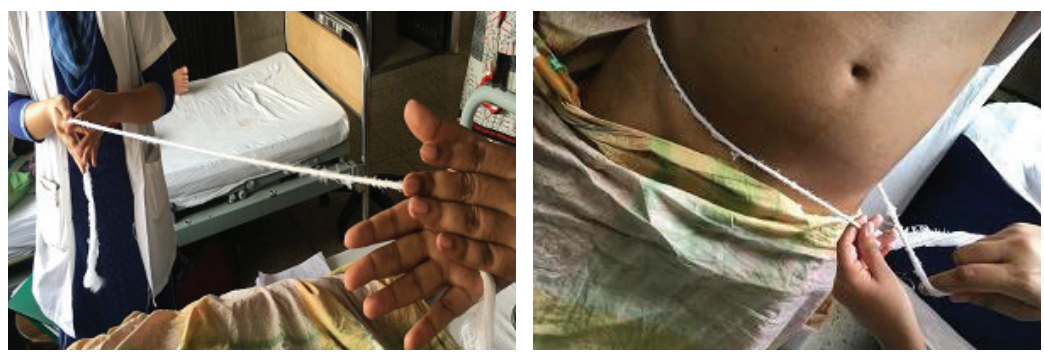

b

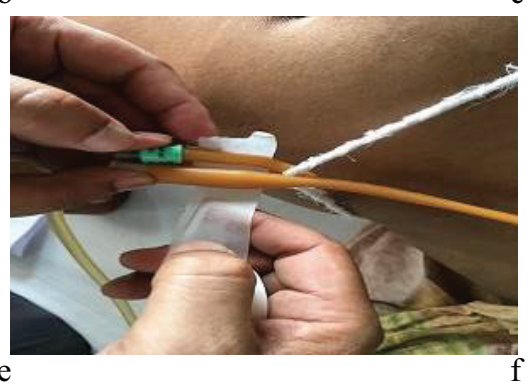

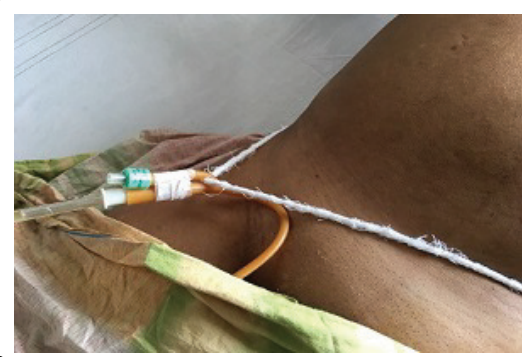

Figure 3 Step by step demonstration of catheter fixation procedure

We are using this over last 6 months in BIRDEM GeneralHospital successfully without any complications. Optimal management of an indwelling catheter includes securing the catheter to the thigh or abdomen in a way that prevents the catheter or its retention balloon from exerting excessive force on the bladder neck or urethra ${ }^{5}$, our procedure is mechanically very much effective in doing this job. In this method, 
accidental pulling of catheter is resisted by encircling loop. Abdominal fixation isalso associated with less meatal trauma and is advised especially for male patients needing long term catheterisation ${ }^{6,7}$.

\section{References}

1. Cule J. Catheters: forerunners of Foley. Nursing mirror 1980;150:Suppl i-vi.

2. Carr HA. A short history of the Foley catheter: from handmade instrument to infection-prevention device. Journal of endourology 2000;14:5-8.

3. Saint S, Lipsky BA. Preventing catheter-related bacteriuria: should we? Can we? How? Archives of internal medicine 1999;159:800-8.

4. Lorente L, Huidobro MS, Martín MM, Jiménez A, Mora ML. Accidental catheter removal in critically ill patients: a prospective and observational study. Critical Care 2004;8:R229-R33.
5. Care of the patient with an indwelling catheter. Urologic nursing 2006;26:80-1.

6. Gray ML. Securing the Indwelling Catheter. AJN The American Journal of Nursing 2008;108:44-50.

7. Emr K, Ryan R. Best practice for indwelling catheter in the home setting. Home healthcare nurse 2004;22:820-8; quiz 930.

8. Hanchett M. Techniques for stabilizing urinary catheters. Tape may be the oldest method, but it's not the only one. The American journal of nursing 2002;102:44-8.

9. Macneil JW, Wilkins RG, Taylor RP, Lau HM. Does the method of "securing the catheter" make any difference? Journal of Clinical Urology 2018;11:21-6.

10. Tracy C. Comparison of catheter-securing devices. Urologic nursing 2000;20:43-6.

11. Wilson M. Catheter lubrication and fixation: interventions. Br J Nurs 2013;22:566, 8-9. 